\title{
A Deterministic Inventory Model for Perishable Items with Lead Time and Price Dependent Demand
}

\author{
S. Kumar ${ }^{1 *}$ and U.S. Rajput ${ }^{2}$ \\ ${ }^{1}$ Dept. of Mathematics \& Astronomy, Lucknow University, Lucknow, India \\ ${ }^{2}$ Dept. of Mathematics \& Astronomy, Lucknow University, Lucknow, India \\ *Corresponding Author: sushilmath4444@gmail.com
}

Available online at: www.isroset.org

Received: 06/May/2018, Revised: 22/May/2018, Accepted: 20/Jun/2018, Online: 30/Jun/2018

\begin{abstract}
In the present paper, an attempt has been made to develop a deterministic inventory model for perishable items with lead time and price dependent demand. Shortages are allowed and completely backlogged. The problem of perishability or deterioration plays an important role in the field of inventory control and management. The purpose of our study is to minimize the total variable inventory cost during a given period of time. A numerical example is given to demonstrate the developed model.
\end{abstract}

Keywords- Inventory, Deterioration, Lead Time and Price Dependent Demand

\section{INTRODUCTION}

Academicians as well as industrialists have great interest in the development of inventory control and their uses. There are many goods which either deteriorate or become obsolete with passage of time. For such perishable products different modeling techniques are applied. Perishable inventory forms a small part of total inventory and includes fashionable garments, electronic items, digital products and periodicals. The perishable products can be classified based on two categories: (1) deterioration (2) obsolescence. Deterioration is defined as damage, decay or spoilage of the items that are stored for future use and which always loose part of their value with passage of time. Obsolescence occurs due to the arrival of new and better products in the market.

In the existing literature, some inventory models which were developed by contemporary researchers considering some or all of the parameters related to constant demand rate, increasing/ decreasing function of time, price and stock dependent have been quoted. The demand of newly arrived products in market is influenced by their prices, because the attractive prices or offers on the products motivate the customers to buy more. This situation increases the order quantity of the retailers or customers. In recent years some researchers also gave their attention towards a time dependent rate, because the demand of newly launched products such as fashionable garments, electronic items, motor vehicles, mobiles etc. increases with time and later it becomes constant.

But in the real life there are many situations in which these assumptions are not valid such as seasonal products, bakery products, electronic items and medicines. Some researches in the area are worth mentioning. Goswami and Chaudhuri [1] developed an EOQ model for deteriorating items with linear trend in demand and shortages. Padmanabhan and Vrat [2] considered an EOQ model for perishable items with stock dependent selling rate. Giri et al. [3] proposed an inventory model for deteriorating items with stock dependent demand rate. Hargia [4] presented an EOQ model for deteriorating items with time varying demand. Giri and Chaudhuri [5] developed a deterministic inventory model for deteriorating items with non-linear holding cost and stock dependent demand rate. Chang and Dye proposed two inventory models [6] and [11]. The model [6] is an EOQ model for deteriorating items with time varying demand and partial backlogging. And the model [11] is an inventory model for perishable items with permissible delay in payments and shortages. Chung et al. [7] presented a note on EOQ models for deteriorating items with stock dependent selling rate. Lin et al. [8] proposed an EOQ model for deteriorating items with time varying demand and allowing shortages. Papachristos and Skouri developed two inventory models [9] and [12]. In model [9] they presented an optimal replenishment policy for deteriorating items with exponential type backlogging rate and time 
varying demand. The model [12] is a continuous review inventory model for deteriorating items with time dependent demand and allowing shortages. Goyal and Giri developed two inventory models [10] and [15]. In model [10] they considered recent trends in modeling of deteriorating inventory. And the model [15] is a production inventory model with time varying demand, production and deterioration rate. Wu [13] proposed an EOQ model for Weibull deteriorating items with time varying demand and allowing shortages. Wang [16] presented a note on EOQ model for perishable items with exponential distribution, deterioration and time dependent demand rate. They also considered shortages in their inventory model. Dye and Ouyang [17] developed an EOQ model for perishable products with stock dependent selling rate and allowing shortages. Shah [18] proposed an inventory model for deteriorating items with time value of money and permissible delay in payments. She considered a finite planning horizon in her inventory model. Hou and Lin [19] developed an EOQ model for deteriorating items with price and stock dependent selling rate. They considered the effect of inflation and time value of money in their inventory model. Dye [20] presented a joint pricing and ordering policy for deteriorating items with partial backlogging. Roy et al. [21] presented an inventory model for deteriorating items with stock dependent demand rate and fuzzy type inflation. They also considered time discounting over a random planning horizon. Min and Zhou [22] developed an inventory model for deteriorating items with stock dependent selling rate and allowing shortages. Jain et al. [23] proposed an inventory model for deteriorating items with fuzzy type inflation and cash discounting over random planning horizon. Panda et al. [24] developed a two warehouse inventory model for deteriorating items with fuzzy type demand rate and lead time. Roy [25] proposed a fuzzy inventory model for deteriorating items with price dependent demand rate. Chaudhary and Sharma [26] presented an inventory model for Weibull deteriorating items with price dependent demand rate under inflation. Maragatham and Palani [27] developed an inventory model for perishable items with lead time, price dependent demand and allowing shortages.

\section{ASSUMPTIONS NOTATIONS}

We consider the following assumptions and notations

1. The demand rate is $R(p)=a p^{-b}, a, b>0$

Here $p$ is the selling price.

2. The deterioration rate is taken as $\theta(t)=\theta t$.

3. $o_{C}$ is the ordering cost per order.

4. $h_{c}$ is the holding cost per unit time.

5. $S_{c}$ is the shortage cost per unit time.

6. $\quad p_{c}$ is the purchase cost per unit time.

7. $T$ is the replenishment cycle length.

8. $I(t)$ is the inventory level at any time $\mathrm{t}$ in $[0, T]$.

9. $T_{1}$ is the time at which inventory level becomes zero.

10. $T C\left(L, T_{1}, T\right)$ is the total variable inventory cost per cycle.

11. The replenishment rate is infinite.

12. The lead time is $L$.

13. There is no repair or replacement of the deteriorated items.

\section{MATHEMATICAL FORMULATION}

Suppose an inventory system contains the maximum inventory level $Q+R(p)$ in the beginning of each cycle, where $R(p)$ is the price dependent demand. During the interval $\left[L, T_{1}\right]$, the inventory level decreases due to both demand and deterioration and it becomes zero at $t=T_{1}$. During the shortage interval $\left[T_{1}, T\right]$ the demand is unsatisfied. The instantaneous inventory level at any time $t$ in $[L, T]$ is given by the following differential equations: 


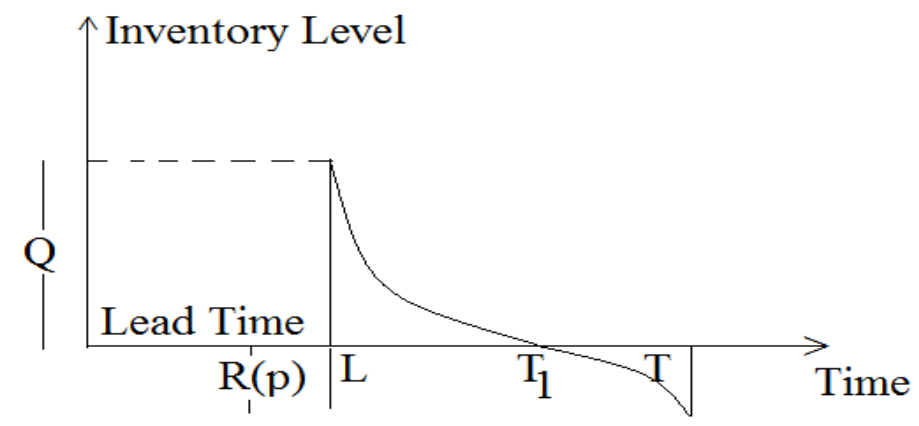

Figure 1, Inventory Model

$\frac{d I}{d t}+\theta t I=-a p^{-b}, \quad L \leq t \leq T_{1}$

$\frac{d I}{d t}=-a p^{-b}, \quad T_{1} \leq t \leq T$

Boundary condition $I\left(T_{1}\right)=0$ is taken in both equations.

The solutions of the equations (1) and (2) are given by the equations (3) and (4) respectively. By considering the first degree terms in $\theta$, we have

$$
\begin{gathered}
I=a p^{-b}\left[T_{1}-t+\frac{\theta}{6} T_{1}^{3}+\frac{\theta}{3} t^{3}-\frac{\theta}{2} T_{1} t^{2}\right] \\
I=a p^{-b}\left[T_{1}-t\right]
\end{gathered}
$$

The maximum inventory level is obtained by putting $t=L$ in equation (3), so

$Q=a p^{-b}\left[T_{1}-L+\frac{\theta}{6} T_{1}^{3}+\frac{\theta}{3} L^{3}-\frac{\theta}{2} T_{1} L^{2}\right]$

The quantity $Q+L D(p)$ is ordered in the beginning of each cycle. The maximum back ordered quantity $I_{B}$ is obtained by putting $t=T$ in equation (4). Therefore

$I_{B}=a p^{-b}\left[T_{1}-T\right]$

The ordering cost per cycle is

$O_{C}=o_{C}$

The holding cost per cycle is

$H_{C}=h_{C} \int_{L}^{T_{1}} I(t) d t$

Or 


$$
H_{C}=a h_{C} p^{-b}\left[\begin{array}{l}
\frac{1}{2} T_{1}^{2}-L T_{1}+\frac{1}{2} L^{2}+\frac{\theta}{12} T_{1}^{4} \\
-\frac{\theta}{12} L^{4}+\frac{\theta}{6} T_{1} L^{3}
\end{array}\right]
$$

The deterioration cost per cycle is

$$
D_{C}=d_{C}\left[Q-\int_{L}^{T_{1}} R(t) d t\right]
$$

Or

$$
D_{C}=a d_{C} p^{-b}\left[\frac{\theta}{6} T_{1}^{3}+\frac{\theta}{3} L^{3}-\frac{\theta}{2} T_{1} L^{2}\right]
$$

The shortage cost per cycle is

$$
S_{C}=-S_{C} \int_{T_{1}}^{T} I(t) d t
$$

Or

$$
S_{C}=a s_{C} p^{-b}\left[\frac{1}{2} T_{1}^{2}+\frac{1}{2} T^{2}-T T_{1}\right]
$$

The purchase cost per cycle is

$$
P_{C}=p_{C}\left[Q+I_{B}\right]
$$

Or

$$
P_{C}=a p_{C} p^{-b}\left[2 T_{1}-T-L+\frac{\theta}{6} T_{1}^{3}+\frac{\theta}{3} L^{3}-\frac{\theta}{2} T_{1} L^{2}\right]
$$

The total variable inventory cost per cycle is

$$
T C\left(L, T_{1}, T\right)=\frac{1}{T}\left[O_{C}+H_{C}+D_{C}+S_{C}+P_{C}\right]
$$

Putting the values of $O_{C}, H_{C}, D_{C}, S_{C}$ and $P_{C}$ in equation (12), we obtain 


$$
\begin{aligned}
& T C\left(L, T_{1}, T\right)=\frac{1}{T}\left[o_{C}+a p^{-b}\left\{2 p_{C} T_{1}-p_{C} L-p_{C} T+\frac{\left(h_{C}+s_{C}\right)}{2} T_{1}^{2}+\frac{h_{C}}{2} L^{2}-h_{C} L T_{1}+\frac{s_{C}}{2} T^{2}-s_{C} T T_{1}\right.\right. \\
& +\frac{\theta\left(d_{C}+p_{C}\right)}{6} T_{1}^{3}+\frac{\theta\left(d_{C}+p_{C}\right)}{3} L^{3}-\frac{\theta\left(d_{C}+p_{C}\right)}{2} T_{1} L^{2} \\
& \left.\left.+\frac{\theta h_{C}}{12} T_{1}^{4}-\frac{\theta h_{C}}{12} L^{4}+\frac{\theta h_{C}}{6} T_{1} L^{3}\right\}\right]
\end{aligned}
$$

The necessary conditions for $T C\left(L, T_{1}, T\right)$ to be minimum are

$\frac{\partial T C\left(L, T_{1}, T\right)}{\partial L}=0, \quad \frac{\partial T C\left(L, T_{1}, T\right)}{\partial T_{1}}=0$ and $\frac{\partial T C\left(L, T_{1}, T\right)}{\partial T}=0$. On solving these equations, we find the optimum values of $L, T_{1}$ and $T$ for which the total variable inventory cost is minimum.

The sufficient conditions for $T C\left(L, T_{1}, T\right)$ to be minimum are that the principal minors of Hessian matrix or $\mathrm{H}$ matrix are positive definite. The Hessian matrix is defined as follows

$$
H=\left[\begin{array}{lll}
\frac{\partial^{2} T C\left(L, T_{1}, T\right)}{\partial L^{2}} & \frac{\partial^{2} T C\left(L, T_{1}, T\right)}{\partial L \partial T_{1}} & \frac{\partial^{2} T C\left(L, T_{1}, T\right)}{\partial L \partial T} \\
\frac{\partial^{2} T C\left(L, T_{1}, T\right)}{\partial T_{1} \partial L} & \frac{\partial^{2} T C\left(L, T_{1}, T\right)}{\partial T_{1}^{2}} & \frac{\partial^{2} T C\left(L, T_{1}, T\right)}{\partial T_{1} \partial T} \\
\frac{\partial^{2} T C\left(L, T_{1}, T\right)}{\partial T \partial L} & \frac{\partial^{2} T C\left(L, T_{1}, T\right)}{\partial T \partial T_{1}} & \frac{\partial^{2} T C\left(L, T_{1}, T\right)}{\partial T^{2}}
\end{array}\right]
$$

Partially differentiating equation (13), we have

$$
\begin{aligned}
& \frac{\partial T C\left(L, T_{1}, T\right)}{\partial L}= \frac{a p^{b}}{T}\left[-p_{C}+h_{C} L-h_{C} T_{1}+\theta\left(d_{C}+p_{C}\right) L^{2}-\theta\left(d_{C}+p_{C}\right) T_{1} L-\frac{\theta h_{C}}{3} L^{3}+\frac{\theta h_{C}}{2} T_{1} L^{2}\right] \\
& \frac{\partial T C\left(L, T_{1}, T\right)}{\partial T_{1}}= \frac{a p^{-b}}{T}\left[2 p_{C}+\left(h_{C}+s_{C}\right) T_{1}-h_{C} L-s_{C} T+\frac{\theta\left(d_{C}+p_{C}\right)}{2} T_{1}^{2}-\frac{\theta\left(d_{C}+p_{C}\right)}{2} L^{2}+\frac{\theta h_{C}}{3} T_{1}^{3}\right. \\
&\left.+\frac{\theta h_{C}}{6} L^{3}\right] \\
& \frac{\partial T C\left(L, T_{1}, T\right)}{\partial T}= \frac{a p^{-b}}{T}\left[-p_{C}+s_{C} T-s_{C} T_{1}\right]-\frac{1}{T^{2}}\left[o_{C}+a p^{-b}\left\{2 p_{C} T_{1}-p_{C} L-p_{C} T+\frac{\left(h_{C}+s_{C}\right)}{2} T_{1}^{2}\right.\right. \\
&+\frac{h_{C}}{2} L^{2}-h_{C} L T_{1}+\frac{s_{C}}{2} T^{2}-s_{C} T T_{1}+\frac{\theta\left(d_{C}+p_{C}\right)}{6} T_{1}^{3}+\frac{\theta\left(d_{C}+p_{C}\right)}{3} L^{3}-\frac{\theta\left(d_{C}+p_{C}\right)}{2} T_{1} L^{2}
\end{aligned}
$$




$$
\begin{aligned}
& \left.\left.+\frac{\theta h_{C}}{12} T_{1}^{2}-\frac{\theta h_{C}}{12} L^{4}+\frac{\theta h_{C}}{6} T_{1} L^{3}\right\}\right] \\
& \frac{\partial^{2} T C\left(L, T_{1}, T\right)}{\partial L^{2}}=\frac{a p^{-b}}{T}\left[h_{C}+2 \theta\left(d_{C}+p_{C}\right) L-\theta\left(d_{C}+p_{C}\right) T_{1}-\theta h_{C} L^{2}+\theta h_{C} T_{1} L\right] \\
& \frac{\partial^{2} T C\left(L, T_{1}, L\right)}{\partial T_{1}^{2}}=\frac{a p^{-b}}{T}\left[\left(h_{C}+s_{C}\right)+\theta\left(d_{C}+p_{C}\right) T_{1}+\theta h_{C} T_{1}^{2}\right] \\
& \frac{\partial^{2} T C\left(L, T_{1},\right)}{\partial L \partial T_{1}}=\frac{a p^{-b}}{T}\left[-h_{C}-\theta\left(d_{C}+p_{C}\right) L+\frac{\theta h_{C}}{2} L^{2}\right] \\
& \frac{\partial^{2} T C\left(L, T_{1}, T\right)}{\partial L \partial T}=-\frac{a p^{-b}}{T^{2}}\left[-p_{C}+h_{C} L-h_{C} T_{1}+\theta\left(d_{C}+p_{C}\right) L^{2}-\theta\left(d_{C}+p_{C}\right) T_{1} L-\frac{\theta h_{C}}{3} L^{3}+\frac{\theta h_{C}}{2} T_{1} L^{2}\right] \\
& \frac{\partial^{2} T C\left(L, T_{1}, T\right)}{\partial T_{1} \partial L}=\frac{a p^{-b}}{T}\left[-h_{C}-\theta\left(d_{C}+p_{C}\right) L+\frac{\theta h_{C}}{2} L^{2}\right] \\
& \frac{\partial^{2} T C\left(L, T_{1}, T\right)}{\partial T_{1} \partial T}=-\frac{a p^{-b} s_{C}}{T}-\frac{a p^{-b}}{T^{2}}\left[2 p_{C}-\frac{\theta\left(d_{C}+p_{C}\right)}{2} L^{2}+\left(h_{C}+s_{C}\right) T_{1}-h_{C} L-s_{C} T+\frac{\theta\left(d_{C}+p_{C}\right)}{2} T_{1}^{2}\right. \\
& \left.+\frac{\theta h_{C}}{3} T_{1}^{2}+\frac{\theta h_{C}}{6} L^{3}\right] \\
& \frac{\partial^{2} T C\left(L, T_{1}, T\right)}{\partial T \partial L}=-\frac{a p^{-b}}{T^{2}}\left[-p_{C}+h_{C} L-h_{C} T_{1}+\theta\left(d_{C}+p_{C}\right) L^{2}-\theta\left(d_{C}+p_{C}\right) T_{1} L-\frac{\theta h_{C}}{3} L^{3}+\frac{\theta h_{C}}{3} T_{1} L^{2}\right] \\
& \frac{\partial^{2} T C\left(L, T_{1}, T\right)}{\partial T \partial T_{1}}=-\frac{a p^{-b} s_{C}}{T}-\frac{a p^{-b}}{T^{2}}\left[2 p_{C}+\left(h_{C}+p_{C}\right) T_{1}-h_{C} L-s_{C} T+\frac{\theta\left(d_{C}+p_{C}\right)}{2} T_{1}^{2}\right. \\
& \left.-\frac{\theta\left(d_{C}+p_{C}\right)}{2} L^{2}+\frac{\theta h_{C}}{3} T_{1}^{3}+\frac{\theta h_{C}}{6} L^{3}\right]
\end{aligned}
$$

Numerically, the Hessian matrix or $\mathrm{H}$ matrix is given by

$$
H=\left[\begin{array}{lcc}
-17.8959 & 17.1981 & 0.0131 \\
17.1981 & 29.5256 & 13.8449 \\
0.0131 & -14.2443 & 9.2057
\end{array}\right]
$$

\section{NUMERICAL EXAMPLE}

Let us consider the following data for parameters in the appropriate units as follows 
$a=300, b=1, o_{C}=100, h_{C}=5, d_{C}=2, s_{C}=8, p_{C}=10, \quad p=25, \quad \theta=0.05$

Table 1, variation in total inventory cost with respect to $\theta$

\begin{tabular}{|l|l|l|l|l|}
\hline$\theta$ & $L$ & $T_{1}$ & $T$ & $T C\left(L, T_{1}, T\right)$ \\
\hline 0.05 & 15.2579 & 6.0163 & 10.4284 & 303.5640 \\
0.10 & 12.4212 & 4.4046 & 8.8553 & 307.2574 \\
0.15 & 11.2630 & 3.7017 & 8.4324 & 334.1419 \\
0.20 & 10.6132 & 3.2903 & 8.3558 & 366.2981 \\
0.25 & 10.1905 & 3.0164 & 8.4296 & 399.6628 \\
\hline
\end{tabular}

From the table 1, we see that if we increase the deterioration parameter $\theta$ then the values of $L, T_{1}$ and $T$ are decreased, but the values of $T C\left(L, T_{1}, T\right)$ get increased.

Table 2, variation in total inventory cost with respect to $a$

\begin{tabular}{|l|l|l|l|l|}
\hline$a$ & $L$ & $T_{1}$ & $T$ & $T C\left(L, T_{1}, T\right)$ \\
\hline 300 & 15.2579 & 6.0163 & 10.4284 & 303.5640 \\
400 & 15.2507 & 6.0088 & 10.3936 & 401.0250 \\
500 & 15.2449 & 6.0028 & 10.3660 & 498.3465 \\
600 & 15.2423 & 6.0000 & 10.3531 & 595.7901 \\
700 & 15.2404 & 5.9981 & 10.3439 & 693.2439 \\
\hline
\end{tabular}

From this table, we see that if we increase the demand parameter $a$, then the values of $L, T_{1}$ and $T$ are decreased, but the values of $T C\left(L, T_{1}, T\right)$ get increased.
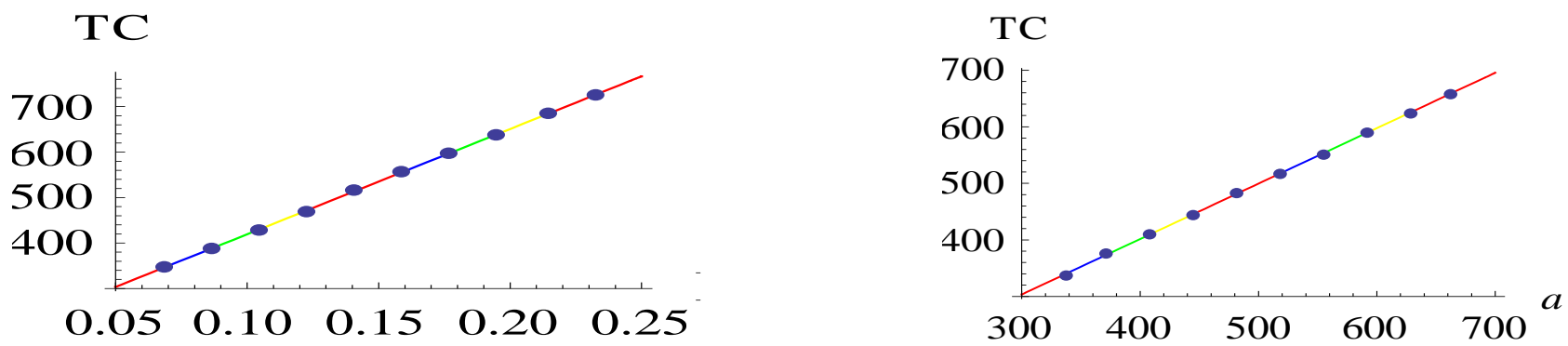

Figure 2, variation in $T C$ with respect to $\theta, \quad$ Figure 3, variation in $T C$ with respect to $a$

Table 3, variation in total inventory cost with respect to $b$

\begin{tabular}{|l|l|l|l|l|}
\hline$b$ & $L$ & $T_{1}$ & $T$ & $T C\left(L, T_{1}, T\right)$ \\
\hline 1 & 15.2579 & 6.0163 & 10.4284 & 303.5640 \\
2 & 15.8578 & 6.6203 & 13.4213 & 21.3155 \\
3 & 19.9962 & 10.1909 & 40.6606 & 4.5005 \\
4 & 30.4007 & 17.8134 & 183.5960 & 1.0255 \\
\hline
\end{tabular}


From this table, we see that if we increase the demand parameter $b$, then the values of $L, T_{1}$ and $T$ are increased, but the values of $T C\left(L, T_{1}, T\right)$ get decreased.

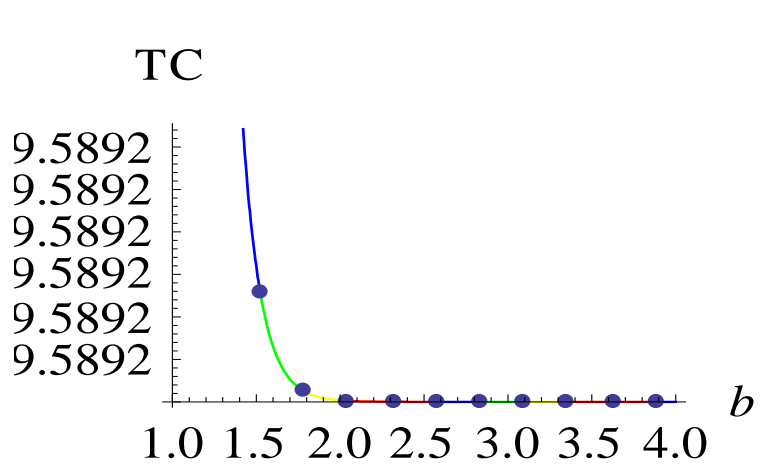

Figure 4, variation in $T C$ with respect to $b$

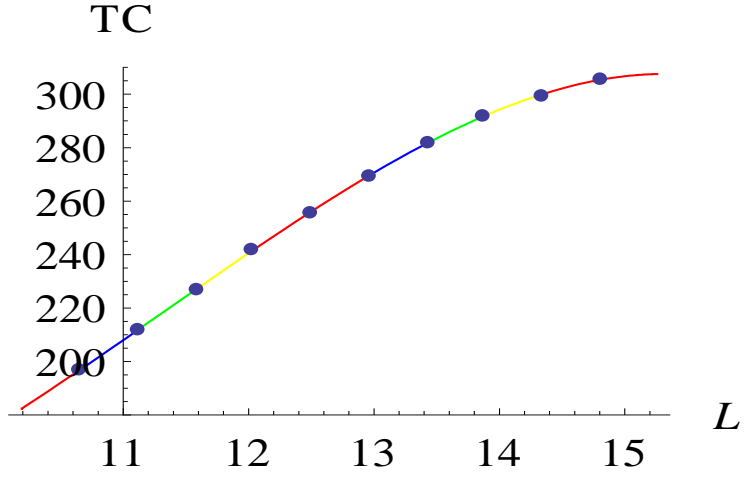

Figure 5, variation in $T C$ with respect to $L$

\section{CONCLUSION}

The results of the proposed model show that the total variable inventory cost is deeply impacted by the parameters $a$ and $b$ in comparison with the parameter $\theta$. This is due to the reason that the newly arrived goods/products in the super market increase the demand. The cycle length and lead time are main components for optimizing the cost/profit of an organization. The products such as vegetables, milk, bakery products and news papers are necessarily to be sold in the market as the cycle length decreases.

\section{REFERENCES}

[1] A. Goswami and K. S. Chaudhuri, "An EOQ model for deteriorating items with linear trend in demand and allowing shortages", Journal of Operational Research Society, Vol. 42, pp.1105-1110,1991.

[2] G. Padmanabhan and P. Vrat, "An EOQ model for perishable items with stock dependent selling rate", European Journal of Operational Research, Vol. 86, pp.281-292, 1995.

[3] B. C. Giri, S. Pal, A. Goswami and K. S. Chaudhuri, "An inventory model for deteriorating items with stock dependent demand rate", European Journal of Operational Research, Vol. 95, pp. 604-610,1996.

[4] M. Hargia, "An EOQ model for deteriorating items with time varying demand”, Journal of Operational Research Society, Vol. 47, pp. 205-213, 1996.

[5] B. C. Giri and K. S. Chaudhuri, "A deterministic inventory model for deteriorating items with stock dependent demand rate and non linear holding cost”, European Journal of Operational Research, Vol.105, pp.464-467,1998.

[6] H. J. Chang and C. Y. Dye, "An EOQ model for deteriorating items with time varying demand and partial backlogging", Journal of Operational Research Society, Vol. 50, pp.1176-1182, 1999.

[7] K. J. Chung, P. Chu and S. P. Lan, "A note on EOQ models for deteriorating items with stock dependent selling rate", European Journal of Operational Research, Vol.124, pp.550-559, 2000.

[8] B. Lin, B. Tan and W. C. Lee, "An EOQ model for deteriorating items with time varying demand and shortages", International Journal of Systems Science, Vol. 31, pp.391-400, 2000.

[9] S. Papachristos and K. Skouri, "An optimal replenish policy for an inventory model of deteriorating items with time varying demand and exponential type acklogging rate", Operations Research Letters, Vol. 27, pp.175-184, 2000.

[10] S. K. Goyal and B. C. Giri, "Recent trends in modeling of deteriorating inventory", European Journal of Operational Research, Vol. 134, pp.1-16, 2001.

[11] H. J. Chang and C.Y. Dye, "An inventory model for deteriorating items with permissible delay in payments and allowing shortages", International Journal of System Science, Vol. 32, pp.345- 352, 2001.

[12] K. Skouri and S. Papachristos, "A continuous review inventory model for perishable items with time dependent demand and partial backlogging”, Applied Mathematical Modeling, Vol. 26, pp.603-617, 2002.

[13] K. S. Wu, "An EOQ model for weibull deteriorating items with time varying demand and partial backlogging" International Journal of Systems Science, Vol. 33, pp.323-329, 2002.

[14] S. P. Wang, "An optimal lot-sizing policy for an inventory model of deteriorating items with time varying demand and shortages", Journal of Chinese Institute of Industrial Engineering, Vol. 20, pp.449-456, 2003.

[15] S. K. Goyal and B. C. Giri, "A production inventory model for deteriorating items with time varying demand rate", European Journal of Operational Research, Vol. 147, pp. 549- 557, 2003. 
[16] W. H. Lee and J. W. Wu, "A note on EOQ model for deteriorating items with exponential distribution deterioration and time dependent demand and shortages" International Journal of Systems Science, Vol.31, pp.677-683, 2004.

[17] Y. Dye and L. Y. Ouyang, "An EOQ model for perishable items with stock dependent selling rate and time dependent artial backlogging", European Journal of Operational Research, Vol. 163, pp.776-783, 2005.

[18] N. H. Shah, "An inventory model for deteriorating items together with time value of money for a finite time horizon under permissible delay in payments", International Journal of Systems Science, Vol. 37, pp.9-15, 2006.

[19] K. L. Hou and L. C. Lin, "An EOQ model for deteriorating items with price and stock dependent selling rate under inflation and time value of money", International Journal ofSystems Science, Vol. 37, pp.1131-1139, 2006.

[20] C. Y. Dye, "A joint pricing andordering policy for deteriorating

items with partial backlogging", Omega-The International Journal Management Science, Vol. 35, pp.184-189, 2007.

[21] A. Roy, M. Maiti and M. K. Kar, "An inventory model for deteriorating items with stock dependent rate and time discounting random planning horizon under fuzzy inflation", Applied

Mathematical Modeling, Vol. 33, pp.744-759, 2009.

[22] J. Min and Y. W. Zhou, "A perishable inventory model for deteriorating items with stock dependent selling rate, shortages together with capacity constraints", International Journal of SystemsScience, Vol. 40, pp.33-44, 2009.

[23] D. K. Jain, B. Das and T. K. Roy, "An inventory model for perishable items with fuzzy type inflation and cash discounting over random planning horizon", Advances in Operations Research, Vol. 2013, pp.1-15, 2013.

[23] D. Panda, M. Rong and M. Maiti, "A two warehouse inventory model for deteriorating items with fuzzy type demand rate and lead time", European Journal of Operations Research, Vol. 22, pp.187-209, 2014.

[24] A. Roy, "Fuzzy inventory model of deteriorating items with price dependent demand rate", International Journal of Management Science and Engineering Management, Vol. 10, Issue. 4, pp.237-241, 2015.

[25] R. R. Chaudhari and V. Sharma, "A model for weibull deteriorating items with price dependent demand rate and inflation", Indian Journal of Science and Technology, Vol. 8, Issue. 10, pp.975-981, 2015.

[26] M. Maragatham and R. Palani, "An inventory model for deteriorating items with lead time, price dependent demand and shortages", Advances in Computational Science and Technology, Vol. 10, Issue. 6, pp.1839-1847, 2017.

\section{AUTHORS PROFILE:}

Mr. Sushil Kumar is an assistant professor in the department of mathematics \& astronomy, lucknow university, lucknow- u.p. (India). His area of specialization is inventory modeling in operations research. He has published $15^{\text {th }}$ research papers in national and international journals.

Dr U S Rajput is a faculty member in the Department of Mathematics \& Astronomy, Lucknow University, Lucknow. He has published more than 100 research papers in reputed international journals including Thomson Reuters (SCI \& Web of Science) and presented papers in many conferences. His research work focuses both in science as well as engineering and technology. He has 28 years of teaching and research experience. 